\title{
Characterisation of Girei Rice Husk Ash for Silica Potential
}

\author{
*Abdullahi M. Usman, *A Raji and *Nuhu. H. Waziri, \\ *Mechanical Engineering Department, Modibbo Adama University Yola, Adamawa State Nigeria.
}

\begin{abstract}
This study was carried out to determine the potential of Girei Rice Husk Ash (RHA) as reinforcement in metal matrix composite. Rice husk from local millers in Girei market in Adamawa state was collected, prepared and burned in metallurgical furnace at temperatures of $500^{\circ} \mathrm{C}, 600^{\circ} \mathrm{C}, 700^{\circ} \mathrm{C}, 800^{\circ} \mathrm{C}$ and $900^{\circ} \mathrm{C}$ and the percentage ash yields determined. The resulting ashes were analysed using X-ray Fluorescence (XRF) machine to determine their chemical oxide composition. The result shows that the resulting ash yield based on mass basis were $19.167 \%, 17.823 \%, 17.572 \%, 21.789 \%$ and $21.826 \%$ at $500^{\circ} \mathrm{C}, 600^{\circ} \mathrm{C}, 700^{\circ} \mathrm{C}, 800^{\circ} \mathrm{C}$ and $900^{\circ} \mathrm{C}$ respectively. The ashes were found to contain high percentage of silica content of $96.841 \%, 96.256 \%$, $97.096 \%, 96.691 \%$ and $96.409 \%$ then followed by alumina content of $0.944 \%, 1.023 \%, 1.135 \%, 1.074 \%$ and $0.965 \%$ at same temperatures respectively. These results shows that rice husk ash produce from Rice from Girei contain high percentage silica and some alumina and can be used in chemical formulations requiring silica such as in metal matrix composites.
\end{abstract}

Key words: rice husk ash, silica, alumina and metal matrix composite

\section{Introduction}

Rice plant is one of the plants that absorbs silica from the soil and assimilates it into its structure during the growth. Rice husk $(\mathrm{RH})$ is the outer covering of the grain of rice plant with a high concentration of silica, generally more than $80-85 \%$. It is responsible for approximately $30 \%$ of the gross weight of a rice kernel and normally contains $80 \%$ of organic and $20 \%$ of inorganic substances. Rice husk is produced in millions of tons per year as a waste material in agricultural and industrial processes. It can contribute about $20 \%$ of its weight to Rice Husk Ash (RHA) (Givi et al, 2010).

Kartini, (2011) report that on average Rice Husk accounts for $20 \%$ of the rice produced on weight basis and the world wide annual husk output is about 120 million tonnes. This waste is problematic during its handling and transportation due to its low density. Actually the rice husk is burnt uncontrolled in open air or used as fuel in the rice paddy milling process, which creates significant environmental problems such as pollution and contamination of springs. Disposal of the husks is a big problem and open heap burning is not acceptable on environmental grounds, and so the majority of husk is currently going into landfill and the content of silica in the ash is about $92-97 \%$. As a result, the use of such ash has stimulated the development of research into the potentialities of this material. According to Shelke et al, (2010) this husk is used as fuel to generate process steam. The husk contains about $75 \%$ organic volatile matter and the balance $25 \%$ of the weight of this husk is converted into ash during the firing process. The ash is known as rice husk ash (RHA).

Several studies have been done on the analysis and use of rice husk ash due to its high silica content among which are Wansom et al (2009) who burnt rice husk from the same source at different burning temperatures and two different conditions. One set was burnt under insufficient $\mathrm{O}_{2}$, while another was burnt under excess $\mathrm{O}_{2}$ both at $600^{\circ} \mathrm{C}, 750^{\circ} \mathrm{C}$, and $900^{\circ} \mathrm{C}$. The silica content of those burnt under insufficient oxygen were $91.39 \%, 93.14 \%$ and $93.59 \%$, while those burnt under excess oxygenwere $93.02 \%, 92.12 \%$ and $93.22 \%$ for 600,750 and $900^{\circ} \mathrm{C}$ respectively. In addition, the samples have high alumina content up to $0.68 \%-1.22 \%$. Kartini, (2011) obtained and used rice husk ash with silica and alumina content of $96.7 \%$ and $1.01 \%$ in his experiment. Oyekan and Kamiyo, (2011) in their experiment used rice husk ash with silica and alumina content of $76.00 \%$ and $3.00 \%$ respectively. Givi et al, (2010) reviewed some work on rice husk from three different researches and found out that their silica contents vary but not significantly. The silica contents were $87.20 \%, 87.3 \%$ and $86.98 \%$.Ngun et al, (2010) uses rice husk ash with silica content of 91.00\%. Prasad and Krishna (2010) used rice husk ash as reinforcement in aluminium matrix having silica content of $90.23 \%$. According to Pydi et al (2012) rice Husk Ash (RHA) on burning gives $14-20 \%$ by weight of Ash which contains $90.23 \%$ by weight silica and minor amounts of other elements. Rice husk is unusually high in ash compared to other biomass fuels close to $20 \%$. The ash is 92 to $95 \%$ silica, highly porous and lightweight, with a very high external surface area (Lingaraju and Krishna, 2011).

The chemical composition of rice husk is found to vary from one sample to another due to the differences in the type of paddy, crop year, climate, property and constituent of the soil and geographical conditions (Habeeb and Mahmud, 2010). Although however, extensive studies have been carried out and most of them have indicated that the silica can be beneficially extracted from rice husk, however, no studyhas been done in the area of study in order to ascertain the composition of RHA from Girei particularly for use in metal 
matrix composite (MMC). This paper is actually one of the series of studies aimed at determining the suitability of the RHA obtained from local rice millers in Girei market for use in MMC. Specially, objectives of the study were to determine the chemical composition of RHA and yields at different burning temperatures.

\subsection{Material}

\section{Material and Methods}

The rice husk was obtained from local rice millers in Girei Market, Girei LGA, Adamawa state Nigeria. The rice husk contained some rice grains and sand mixed together both in particles and powdered form.

\subsection{Equipment and Tools}

The equipments used in the research include metallurgical furnace of temperature range of $\left(0-1200^{\circ} \mathrm{C}\right)$, tong, stainless steel trays and containers, electric balance, spoon etc in the department of Mechanical Engineering Department laboratory, Modibbo Adama University of Technology, Yola, Adamawa state.Others include somatic C7-621 grinding and Herzog pelleting machines made by Herzog Company Ltd, stearic acid, pelleting dish, computer and X-ray Fluorescence machine in Ashaka cement Plc. Bajoga Gombe state.

\subsection{Rice Husk Preparation}

The RH was first blown manually to separate the husk from rice grain and some sand particles it was then washed with tap water three times while stirring to allow the sand particles to settle at the bottom. The powdered grains and sand mixed with the water became muddy. This muddy water was then poured away and the rice husk was manually removed from the container leaving behind the settled sand. The washed rice husk was then dried under sun rays for three days on stainless steel trays.

\subsection{Burning of Rice Husk}

The rice husk was loaded in a stainless steel container and burn at a temperature of $500^{\circ} \mathrm{C}, 600^{\circ} \mathrm{C}$, $700^{\circ} \mathrm{C}, 800^{\circ} \mathrm{C}$ and $900^{\circ} \mathrm{C}$ in metallurgical furnace for a period of two hours and the corresponding average masses of the rice husk $\mathrm{W}_{1}$, ash $\mathrm{W}_{2}$ after burning were measured using electric balance and the mass burnt away $\mathrm{W}_{3}$ was calculated. These values together with the percentage remain and losses were recorded.

Table 1: Rice husk before and after burning at different temperatures

\begin{tabular}{c|ccccc}
\hline Temperature & $\mathrm{W}_{1}(\mathrm{~g})$ & $\mathrm{W}_{2}(\mathrm{~g})$ & $\mathrm{W}_{3}(\mathrm{~g})$ & \%Ash & \%Loss \\
\hline 500 & 500 & 95.84 & 404.17 & 19.17 & 80.83 \\
600 & 500 & 89.12 & 410.89 & 17.82 & 82.18 \\
700 & 500 & 87.86 & 412.14 & 17.57 & 82.43 \\
800 & 500 & 108.95 & 391.06 & 21.79 & 78.21 \\
900 & 500 & 109.13 & 390.87 & 21.83 & 78.17 \\
\hline
\end{tabular}

\subsection{Ash Preparation and Chemical Composition Analysis}

The RHA was first ground to powder in a somatic C7-621 grinding machine for 60s. The milled RHA of $20 \mathrm{~g}$ was mixed with approximately $0.4 \mathrm{~g}$ of stearic acid as flux and binder and put into the grinding machine for another 60s. This prepared sample was used to produce pellets for analysis. One third of the pelleting dish was filled with stearic acid and the remaining volume filled with the ash sample. The dish together with the sample and stearic acid was put into Herzog pelleting machine and pelleted at force of $200 \mathrm{kN}$. The pellets were then put in to analysis hole of XRF machine for chemical composition analysis. The required constituents in the ash were analysed using analysis of variance technique (ANOVA) to show if there is a different between the mean of the levels at $5 \%$ significance level.

Table 2: Average percentage chemical compositions of rice husk ash after burning

\begin{tabular}{c|cccccccccc}
\hline $\mathrm{T}\left({ }^{\circ} \mathrm{C}\right)$ & $\mathrm{SiO}_{2}$ & $\mathrm{Al}_{2} \mathrm{O}_{3}$ & $\mathrm{Fe}_{2} \mathrm{O}_{3}$ & $\mathrm{CaO}$ & $\mathrm{MgO}$ & $\mathrm{SO}_{3}$ & $\mathrm{~K}_{2} \mathrm{O}$ & $\mathrm{Na}_{2} \mathrm{O}$ & Others & $\mathrm{LOI}$ \\
\hline 500 & 96.84 & 0.94 & 0.34 & 0.24 & 0.83 & 0.18 & 0.06 & 0.07 & $\mathrm{Bal}$ & 1.10 \\
600 & 96.26 & 1.02 & 0.31 & 0.08 & 1.06 & 0.13 & 0.55 & 0.10 & $\mathrm{Bal}$ & 1.23 \\
700 & 97.10 & 1.14 & 0.32 & 0.07 & 0.83 & 0.15 & 0.18 & 0.09 & $\mathrm{Bal}$ & 0.97 \\
800 & 96.69 & 1.07 & 0.94 & 0.04 & 0.80 & 0.09 & 0.21 & 0.08 & $\mathrm{Bal}$ & 0.92 \\
900 & 96.41 & 0.97 & 1.43 & 0.03 & 0.79 & 0.08 & 0.26 & 0.06 & $\mathrm{Bal}$ & 0.89 \\
\hline
\end{tabular}


Table 3: Analysis of variance of the combined silica and alumina content of thesamples

\begin{tabular}{ccccccc}
\hline Source & Sum of Squares & Df & Mean Square & F-test & Significance & Remark \\
\hline Treatment & 1.730 & 4 & 0.433 & 173.751 & 0.000 & $\mathrm{~S}$ \\
Error & 0.025 & 10 & 0.002 & & & \\
Total & 1.755 & 14 & & & & \\
\hline
\end{tabular}

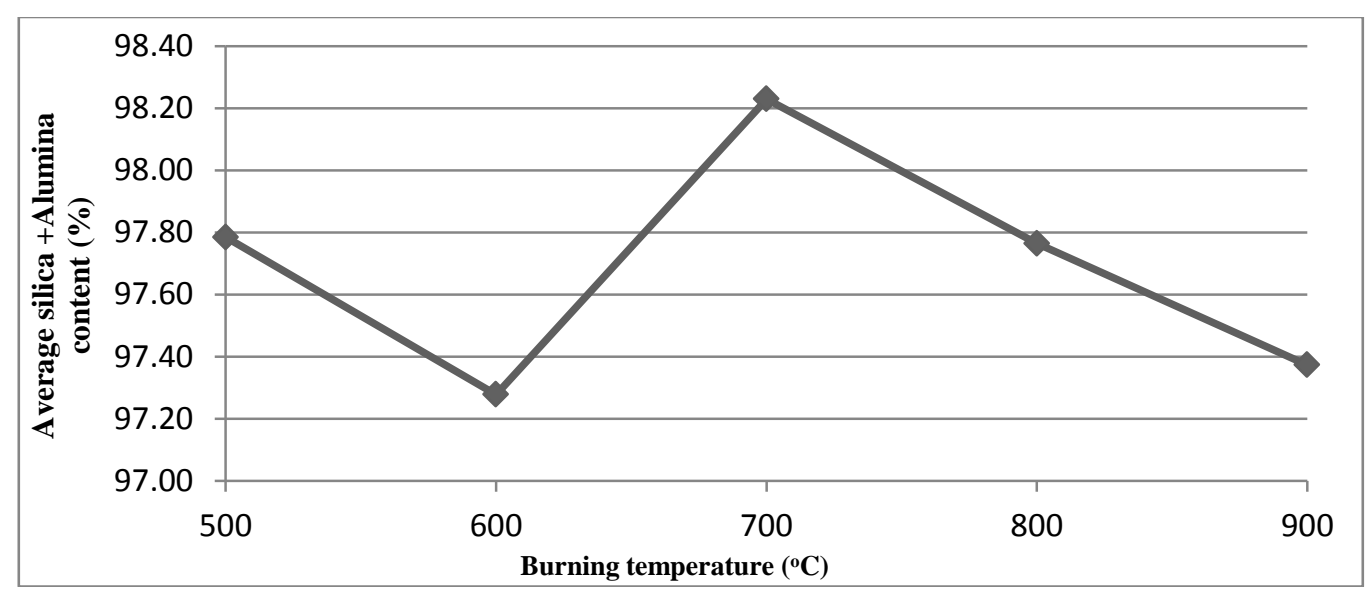

Figure 1: Variation of silica + Alumina content of the ash with the temperature of burning

\section{Results and Discussion}

Table 1 show the masses of RH before and RHA after burning at temperatures $500^{\circ} \mathrm{C}, 600^{\circ} \mathrm{C}, 700^{\circ} \mathrm{C}$, $800^{\circ} \mathrm{C}$ and $900^{\circ} \mathrm{C}$ and the corresponding mass percentage of RHA ash remain and loss after burning. Table 2 show the chemical composition analysis of the ash produced after burning at the different temperatures. Table 3 show the analysis of variance between the different mean of the combined silica and alumina content in the rice husk ash at 5\% significance level. The variation of mass percentage content of combined silica and alumina with temperature is given in Figure 1. From Table 1 the percentage masses of ash remain were in the range of $17.57 \%$ to $21.83 \%$ and was high at temperatures $800^{\circ} \mathrm{C}$ and $900^{\circ} \mathrm{C}$ followed by $500^{\circ} \mathrm{C}$ then $600^{\circ} \mathrm{C}$ and least at $700^{\circ} \mathrm{C}$. It shows that high quality ash considering silica and alumina content will be gotten at $700^{\circ} \mathrm{C}$ as proper and complete burning leads to high loss in weight by losing all the carbonaceous and volatile matter in the rice husk which is in conformity with result reported in Bandara, (1994), Wansom et al, (2009), Givi et al, (2010), Habeeb and Mahmud, (2010), Shelke et al, (2010). Temperatures $800^{\circ} \mathrm{C}$ and $900^{\circ} \mathrm{C}$ produce high percentage ash because of possibility of some of the carbonaceous material reacting with silica and other materials in the husk. From Table 1 percentage loss at $700^{\circ} \mathrm{C}$ is high followed by $600^{\circ} \mathrm{C}$ and $500^{\circ} \mathrm{C}$. This clearly explain that high quality ash will be obtain at 700 considering removing all the volatile matter without allowing them to react with any material in the husk during burning. From Table 2 and Figure 1 the silica and alumina content ranges from $97.28 \%$ at $600^{\circ} \mathrm{C}$ to $98.24 \%$ at $700^{\circ} \mathrm{C}$. These result conformed with the result reported in Katini, (2011) and even have higher silica and alumina content compared with result reported in Sivakumar and Ravibaskar, (2009), Wansom et al, (2009), Givi, et al, (2010), Ngun et al, (2010), Habeeb and Mahmud, (2010), Shelke et al, (2010), Oyekan and Kamiyo, (2011), This shows that ash obtained from rice husk in Girei Adamawa state are good source of silica and alumina and it can be use were silica and alumina are needed as stating or reinforcing material such as metal matrix composites. From Table 3, it can be seen that there is a significant difference between the means of the different levels.

\section{Conclusion}

From the research the following conclusions were drawn:

1. An average of $19.17 \%, 17.82 \%, 17.57 \%, 21.79 \%$ and $21.83 \%$ respectively of ash remained after burning the rice husk at $500^{\circ} \mathrm{C}, 600^{\circ} \mathrm{C}, 700^{\circ} \mathrm{C}, 800^{\circ} \mathrm{C}$ and $900^{\circ} \mathrm{C}$ respectively.

2. Rice husk ash is a one of the abundant agricultural waste having high silica content when burnt.

3. Average of $96.84 \%, 96.26 \%, 97.10 \%, 96.69 \%$ and $96.41 \%$ silica was obtained from the RHA by simple burning rice husk at the same temperatures respectively.

4. Alumina content ranges from $0.94 \%, 1.02 \%, 1.14 \%, 1.07 \%$ and $0.97 \%$ at the same temperatures respectively.

5. Rice husk ash is a good pozzolanic material as pozzolana are material having high silica and alumina content. 
6. $700^{\circ} \mathrm{C}$ was the temperature at which optimum property were obtained.The quantity of silica in the ash obtained in this work is higher than that obtained by several authors.

7. Therefore it can be used were silica and alumina are needed for starting or processing materials as compared to ash obtained in different countries such as metal matrix composites.

\section{Recommendation}

1. The ash contained oxides of alkali and alkaline earth metal which can be reduced to bearest minimum by reacting the ash with solution of acid such as $\mathrm{HCl}$ so that higher silica can be recovered.

2. Complete analysis of rice husk to be carried out to draw general or individual conclusions for the various rice farming region in states and the country as a whole.

\section{Acknowledgement}

The authors will like to acknowledge the contribution made by Ashaka cement Plc. Bajoga, Gombe state and the Department of Mechanical Engineering Department Modibbo Adama University, Yola Adamawa Statein given us the accessibility to their machines and tools for preparation and analysis of the samples.

\section{References}

[1] Bandara, D. H. M. S. (1994). Development of Blended Cement Utilising the Pozzolanic Amorphours Silica components of rice Husk Ash. Journal of National Science Council Sri Lanka, 22(2), 189-199.

[2] Givi, A. N.; AbdulRashid, S.; AbdulAziz, F. N. and Mohamad Salleh, M. A. (2010). Contribution of Rice Husk Ash to the Properties of Mortar and Concrete: A Review. Journal of American Science, 6(3), 157-165.

[3] Habeeb, G. A. and Mahmud, H. B. (2010). A study on Properties of Rice Husk Ash and its Use as Cement Replacement Material. Material Research, 13(2), 185-190.

[4] Kartini, K. (2011). Rice husk Ash-Pozzolanic Material for Sustainability. International Journal Of Aplied Science and Technology, 1(6), 169-178.

[5] Lingaraju, D. and Krishna, P. M. (2011). Studies on Hardness of Rice Husk Ash Polymer Hybrid Nano Composites by Burnishing Process. International journal of Advanced Scientific and Technical Research, 2(1), 438-447.

[6] Ngun, B. K.; Mohamad, H.; Sakai, E. and Ahmad, Z. A. (2010). Effect Of Rice Husk Ash And Silica Fume In Ternary System On The Properties Of Blended Cement Paste And Concrete. Journal of Ceramic Processing Research, 11(3), 311-315.

[7] Oyekan, G. L. and Kamiyo, O. M. (2011). A Study on the Engineering Properties of Sandcrete Blocks Produced With Rice Husk Ash Blended Cement. Journal of Engineering and Technology Research, 3(3), 88-98. Retrieved from http://www.academicjournals.org/JETR

[8] Prasad, D. S. and Krishna, A. R. (2010). Fabrication and Characterization of A356.2-Rice Husk Ash Composite Using Stir Casting Technique. International Journal of Engineering Science and Technology, 2(12), 7603-7608.

[9] Pydi, H. P.; Prasad Saripalli, H. K. R.; Abburi, M. R.; Murthy, B. S. N. and Sivaprasad, D. (2012). Scanning Electron Microscope Studies on Dry Sliding Wear Behaviour of Metal Matrix Composites With Aluminium and Rice Husk Ash. International Journal of Integrative sciences, Innovation and Technology, 1(2), 1-5.

[10] Shelke, V. R.; Bhagade, S. S. and Mandavgane, S. A. (2010). Mesoporous Silica from Rice Husk Ash. Bulletin of Chemical Reaction Engineering \& Catalysis, 5(2), 63-67.

[11] Sivakumar, G. and Ravibaskar, R. (2009). Investigation on the Hydration Properties of the Rice Husk Ash Cement Using Ftir and Sem. Applied Physics Research, 1(2), 71-77.

[12] Wansom, S.; Janjaturaphan, S. and Sunthupinyo, S. (2009). Pozzolanic Activity of Rice Husk Ash : Comparison of Various Electrical Methods. Journal of Metals, Materials and Minerals, 19(2), 1-7. 